\title{
Suspended Affixation Needs No Morphological Word: the suffix -(y)Ip
}

\author{
Furkan Atmaca*
}

\begin{abstract}
I re-evaluate the morphological word constraint for suspended affixation (SA) in Turkish (Kabak, 2007). I argue that SA, as an operation, is not bound by the morphological word constraint. What is constrained is the exponent insertion after SA. SA is a morphological ellipsis taking place in conjunctions. After suspension, affixes on the conjunction periphery are interpreted for all the conjuncts. The morphological word constraint in Turkish is related to SA in verbals, and it defines the limit of suspendability for an affix. This limit is defined by Kabak to be the morphological word. What is left of the conjunct after suspension should be a morphological word otherwise the derivation is ungrammatical. To show that this is not the case, I propose a different analysis for the suffix $-(y) I p$ and provide empirical points for its relation to SA.
\end{abstract}

Keywords. suspended affixation; Turkish; morphology; conjoiner

1. Introduction. Suspended affixation (SA) is a morphological ellipsis process observed in conjunctions, and the term is first coined by Lewis (1967) for Turkish. In SA, affixes on the conjunction periphery are interpreted for all the conjuncts and it is derived from fully specified conjunctions (1). ${ }^{1}$ It is observed in other languages like Ossetic (Erschler, 2012, 2018), Mari (Guseva \& Weisser, 2018), Korean (Yoon, 2017), and German (Pounder, 2006).

(1) Suffix suspension

a. $\mathrm{CONJ}_{1}-\alpha, \ldots \mathrm{CONJ}_{i}-\alpha \Rightarrow \mathrm{CONJ}_{1}, \ldots \mathrm{CONJ}_{i}-\alpha$

Prefix suspension

b. $\beta-\mathrm{CONJ}_{1}, \ldots \beta-\mathrm{CONJ}_{i} \Rightarrow \beta-\mathrm{CONJ}_{1}, \ldots \mathrm{CONJ}_{i}$

1.1 SA IN TURKISH. SA in Turkish applies to nominal and verbal affixes. In the nominal domain, SA of PL and POSS is ambiguous but SA of CASE is unambiguous (2). These affixes can be stacked on top of one another (PL-POSS-CASE) and be subject to varying number of suspension configurations. The grammaticality for one possible configuration, suspension of POSS in the context of PL (3), is debated (Kabak, 2007; Orgun, 1995).

a. silgi-(ler) ve kalem-ler
eraser-(PL) AND pencil-PL

SA: 'Erasers and pencils'

No SA: 'An eraser and pencils'

\footnotetext{
*I thank the anonymous reviewers and participants on Tu+6 for their questions and comments. Any errors are my own. Author: Furkan Atmaca, Universität Leipzig (furkanatmaca@ outlook.com.tr)

${ }^{1} 1$ = first person, $2=$ second person, $3=$ third person, $\mathrm{ABIL}=$ ability, $\mathrm{ACC}=$ accusative, $\mathrm{AND}=\mathrm{and}, \mathrm{AOR}=\mathrm{aorist}, \mathrm{BY}=$ derivational $-(y) A r A K, \mathrm{CASE}=$ case, $\mathrm{CAUS}=$ causative, $\mathrm{CON}=$ conative, $\mathrm{COND}=$ conditional, $\mathrm{CONT}=$ aspect $\mathrm{con}-$ tinuant, $\mathrm{COP}=$ copula, $\mathrm{DAT}=$ dative, $\mathrm{DUR}=$ durative, $\mathrm{FOC}=$ focus, $\mathrm{FUT}=$ future, $\mathrm{NEC}=$ necessitive, $\mathrm{NEG}=\mathrm{negative}$, $\mathrm{NOM}=$ nominative, $\mathrm{ORD}=$ ordinal, $\mathrm{PASS}=$ passive, $\mathrm{PC}=$ predicate concatenator, $\mathrm{PL}=$ plural, $\mathrm{POSS}=$ possessive , $\mathrm{PRF}=$ perfect, $\mathrm{PROG}=$ progressive, $\mathrm{PST}=$ past, $\mathrm{Q}=$ question particle, $\mathrm{RECP}=$ reciprocal, $\mathrm{REFL}=$ reflexive, $\mathrm{SG}=$ singular, WHEN = derivational $-(y) \operatorname{Inc} A$, WO $=$ derivational $-m A d A n$. I am using capital letters for phonological segments which are subject to assimilation processes. ' $I$ ' for harmonizing to /u/, /I/, /u/, and /y/. 'A' for harmonizing to $/ \mathrm{a} / \mathrm{and} / \mathrm{e} /$, ' $\mathrm{K}$ ' for assimilating to $/ \mathrm{\gamma} /$ and $\varnothing$. Some Turkish orthography and their IPA equivalents: $\mathrm{c}=/ \mathrm{d} /, 1=/ \mathrm{u} /$, $\mathrm{s}=/ \mathrm{j} / \mathrm{y}=/ \mathrm{j} /$
} 

b. silgi-(m) ve kalem-im
eraser-(1SG.POSS) AND pencil-1SG.POSS

SA: 'My eraser and my pencil'

No SA:'The eraser and my pencil'"2

c. silgi-(yi) ve kalem-i al-d1-m.

eraser-(ACC) AND pencil-ACC take-PST-1SG

SA: 'I took the eraser and the pencil.'

(3) Kalem-ler-(?im) ve kitap-lar-1m

pencil-PL-(1SG.POSS) AND pencil-PL-1SG.POSS

SA:'?My pencils and my books'

No SA: 'The pencils and my books'

In the verbal domain, all suspendable affixes result in unambiguous readings (4). SA in the verbal domain is bound by the morphological word constraint that defines the suspendable affixes. If what is left of the conjunct(s) after suspension is a morphological word, the resulting configuration is grammatical. The boundary for morphological word status is the set of affixes: PROG, AOR, FUT, NEC, and all agreement markers (Kabak, 2007).

(4) SA in the verbal domain

a. Koş-*(uyor-(um)) ve düş-üyor-um. run-*(PROG-(1SG)) AND fall-PROG-1SG

'I am running and falling.'

b. $\operatorname{Koş}_{-*}^{*}(\mathrm{tu}-*(\mathrm{~m}))$ ve düş-tü-m. run-*(PST-*(1SG)) AND fall-PST-1SG

'I ran and fell.'

c. $\operatorname{Koş}^{*}($ uyor- $(\mathrm{du}-*(\mathrm{~m})))$ ve düş-üyor-du-m. run-*(PROG-(PST-*(1SG))) AND fall-PROG-PST-1SG

'I was running and falling.'

There are multiple agreement paradigms in Turkish, and the ones relevant for suspendability are the z-paradigm and the k-paradigm agreement markers. The paradigms are provided in Table 1, z-paradigm markers are suspendable while k-paradigm ones are not. ${ }^{3}$

\begin{tabular}{|c|cc|cc|}
\cline { 2 - 5 } \multicolumn{1}{c|}{} & \multicolumn{2}{|c|}{$\begin{array}{c}\text { k-paradigm } \\
\text { PST, COND }\end{array}$} & \multicolumn{2}{|c|}{$\begin{array}{c}\text { z-paradigm } \\
\text { AOR, FUT, PROG, } \\
\text { PRF, NEC, COP }\end{array}$} \\
\cline { 2 - 5 } & sg & pl & sg & pl \\
\hline 1 & $-\mathrm{m}$ & $-\mathrm{k}$ & $-\mathrm{Im}$ & $-\mathrm{Iz}$ \\
3 & $-\mathrm{n}$ & $-\mathrm{nIz}$ & $-\mathrm{sIn}$ & $-\mathrm{sInIz}$ \\
& $\varnothing$ & $-1 \mathrm{Ar}$ & $\varnothing$ & $-\mathrm{AAr}$ \\
\hline
\end{tabular}

Table 1: k- and z-paradigms in Turkish

\footnotetext{
${ }^{2}$ The change in translation from 'a' to 'the' is not accidental. This comes about as a result of semantic equivalence in conjunctions (Munn, 1993) and constructions after SA are still bound by this equivalence.

${ }^{3}$ Paradigms are named after the first consonant of the 1PL exponent
} 
SA is mostly observed in inflectional affixes, but there are marginal examples of derivational affixes being suspended like in (5). The analyses for such cases are divided between conjunction in the lexicon (Kabak, 2007) and relaxed lexical integrity (Akkuş, 2016). ${ }^{4}$ In this study, I only discuss SA of inflectional affixes.

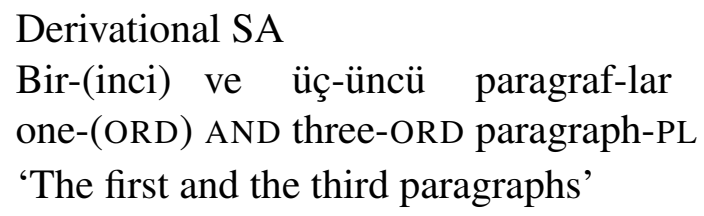

1.2 OUTLINE. I introduced SA in Turkish so far. In $\S 2$, I present some data with an environment created by $-(y) I p$ in Turkish. I show that it is a conjunction environment and not much different than the free form conjoiner $v e$ 'and.' In $\S 3$, I lay out the analysis of Kabak (2007) and propose that the morphological word constraint is not a constraint regulating SA as an operation, but it is related to the vocabulary insertion of the conjoiner. In $\S 4$, I discuss the nature of what a morphological word may be in Turkish. In $\$ 5$, I make conclusions.

2. Data. SA is mostly considered within the conjunctions formed by ve 'and.' A possible conjunction environment in Turkish is formed by the affix $-(y) I p$ (PC in glosses). It receives two analyses in the literature: (i) converb adverbial (Demir, 2014; Göksel \& Kerslake, 2004; Underhill, 1976) and (ii) converb conjoiner (Fokkens et al., 2009; Johanson, 1995; Kornfilt, 1997).

If -(y)Ip were to be interpreted as a marker that turns verbal expressions into adverbials, one should expect it to behave like other adverbial markers such as - (y)Inca 'when V,' $-m A d A n$ 'without Ving (...), and - $(y) A r A K$ 'by Ving (...)' (glossed as WHEN, wO, and BY respectively) in Turkish. There is a configurational asymmetry between $-(y) I p$ and the two adverbial markers $-(y)$ Inca and $-m A d A n(6){ }^{5}$

The structural unit marked by $-(y) \operatorname{Inc} A$ and $-m A d A n$ can have their own separate argument structure, thereby contributing to the matrix verb as one independent unit.
a. Ali düş-ünce Mehmet dur-du. A[NOM] fall-WHEN M[NOM] stop-PST
c. *Ali düş-üp Mehmet dur-du. $\mathrm{A}[\mathrm{NOM}]$ fall-PC M[NOM] stop-PST 'Mehmet stopped when Ali fell.'
b. Ali düş-meden Mehmet dur-du. A[NOM] fall-WO M[NOM] stop-PST
d. *Ali düş-erek Mehmet dur-du. $\mathrm{A}[\mathrm{NOM}]$ fall-BY $\mathrm{M}[\mathrm{NOM}]$ stop-PST 'Mehmet stopped before Ali fell.'

\footnotetext{
${ }^{4}$ Broadwell (2008); Kornfilt (1996, 2012) further provide differing frameworks and analyses for SA in Turkish, like Lexical Functional Grammar and Right Node Raising.

${ }^{5}(6 \mathrm{c})$ can be made grammatical by a topicalized argument or an adjunct (i), but that falls out of the focus of this study. The requirement for topicalization can be related to other factors than $-(y) I p$ being a conjoiner or not.
}

(i) a. Kitab-1 Ali al-1p Mehmet sat-t1. book-ACC A[NOM] buy-PC M[NOM] sell-PST

b. Kitab-1 Ali al-dı ve Mehmet sat-tı. book-ACC A[NOM] buy-PST AND M[NOM] sell-PST 'Ali bought the book and Mehmet sold it.' 
The asymmetry between the pairs ' $-(y) \operatorname{IncA},-m A d A n$ ' $(6 \mathrm{a}, 6 \mathrm{~b})$ versus ' $-(y) \operatorname{Ip},-(y) A r A K$ ' $(6 \mathrm{c}-6 \mathrm{~d})$ is not enough to rule out $-(y) I p$ as an adverbial marker. In addition to the difference in (6), $-(y) I p$ contrasts with $-(y) A r A K$ in terms of possible word orders (7a) and verb-manner compatibility (7b). This means that the $-(y) I p$ marked structural unit has two degrees of separation from the adverbial markers - $(y) \operatorname{IncA}$ and $-m A d A n$; additionally, it has one degree of separation from the adverbial marker $-(y) A r A K$.

$$
\begin{aligned}
\text { a. i. } & \text { *Koş-up Ahmet gel-di. } \\
& \text { run-PC A[NOM] come-PST[3SG] } \\
& \text { Intended:'Ahmet ran and came.' } \\
\text { ii. } & \text { Koş-arak Ahmet gel-di. } \\
& \text { run-BY A[NOM] come-PST[3SG] } \\
& \text { 'Ahmet came running.' }
\end{aligned}
$$

b. i. Ahmet koş-up uyu-du. $\mathrm{A}[\mathrm{NOM}]$ run-PC sleep-PST[3SG] 'Ahmet ran and slept.'

ii. \%Ahmet koş-arak uyu-du. $\mathrm{A}[\mathrm{NOM}]$ run-BY sleep-PST[3SG] '\%Ahmet slept running.'

I take the observations made in (6) and (7) to argue a conjoiner analysis for $-(y) I p$. In the converb conjoiner analyses (Fokkens et al., 2009; Johanson, 1995; Kornfilt, 1997), -(y)Ip conjoins verbs or verb phrases (small conjunction). The voice changing affixes (RECP, REFL, CAUS, PASS), negation (NEG), and some modality markers (ABIL, CON) can intervene between the verb and - $(y) I p$. These affixes can also be stacked (8). If we assume some or at least one of these markers are exponents of inflectional projections (Cinque, 1999, 2002), then the analysis of simple verb conjunction needs reevaluation.
Atık-lar dön-üş-tür-ül-e-me-yiver-ip
at-1l-d1.
waste-PL turn-RECP-CAUS-PASS-ABIL.NEG-NEG-CON-PC throw-PASS-PST
'The waste was not being able to be recycled quickly and (it was) thrown out.'

Some in the literature (Akkuş, 2019; Kratzer, 1996; Pylkkänen, 2008) already propose higher structures than VPs for causative voice and the arguments. Changes in the argument structure might need higher projections than VPs. (9) shows that causees can belong to the separate conjuncts in - $(y) I p$ constructions. The most outer argument in a sentence can be under a $-(y) I p$ marked conjunct, once again making it difficult to maintain a smaller conjunction analysis for $-(y) I p$ versus $v e .^{6}$

(9) Ev-i Mehmet-e Ahmet sat-tır-1p Ali y1ka-t-ti. house-ACC M-DAT A[NOM] sell-CAUS-PC A[NOM] wash-CAUS-PST

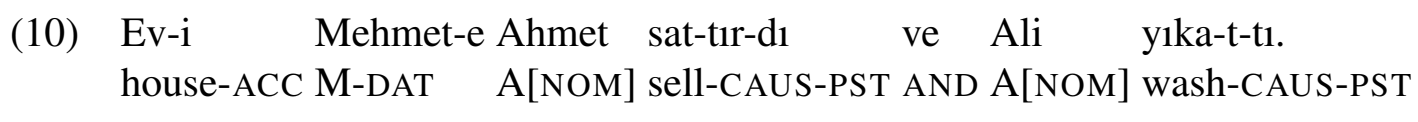

'Ahmet made Mehmet $_{i}$ sell the house and Ali made him $i$ wash it.'

There are additional observations showing that conjuncts in $-(y)$ Ip constructions can differ in time adverbials (11a), contrast in negation (11b), or its scope (11c).

\footnotetext{
${ }^{6}$ Please note that in (9) there is no requirement of voice affixes being parallel, the verb sat-tır-ıp 'sell-CAUS-PC' can be replaced with ver-ip 'give-PC,' the result is still grammatical.
} 
a. Different time adverbials

Bugün çalış-ıp yarın gid-ecek.

today work-PC tomorrow leave-FUT[3SG]

'S/he will work today and leave tomorrow.'

b. Unequal phrase level

Bugün çalış-a-ma-yıp yarın gid-ecek.

today work-ABIL.NEG-NEG-PC tomorrow leave-FUT[3 $\mathrm{SG}$ ]

'S/he will not be able to work today and will leave tomorrow.'

c. Ambiguous scope

Bugün çalış-1p yarın git-me-yecek.

today work-PC tomorrow leave-NEG-FUT[3SG]

1:'S/he will not work today and will not leave tomorrow.'

$2:$ 'S/he will work today but will not leave tomorrow.'

The observation in (11c), ambiguous scope of negation, is problematic if one assumes small conjunction for $-(y) I p$. The first reading of (11c) would require raising the first conjunct out of the negation scope, a move that would violate both Coordinate Structure Constraint (Ross, 1967) and Phase Impenetrability Condition (Chomsky, 2001). Both constraints are respected in Turkish $(12,13){ }^{7}$

CSC is respected in Turkish
a. *Kim ve Ali ev-e gel-di?
who AND A[NOM] house-DAT come-PST
Intended: '*Who and Ali came home?'

b. ??Ali ve kim ev-e gel-di?

$\mathrm{A}[\mathrm{NOM}] \mathrm{AND}$ who house-DAT come-PST

Intended: '??Ali and who came home?'

(13) PIC is violated if $\mathrm{CONJ}_{1}$ moves, (it is not the phase edge).

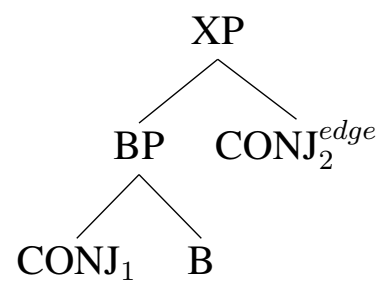

It is clear by the arguments made so far that assigning different roles of conjunction to ve and $-(y) I p$ is difficult. If one takes these two exponents to be conjoiners, assigning different syntactic flavours to them is taxing. That is why, the null hypothesis should be to assume that these two exponents are syntactically the same. The distinction, then, is dependent on the surface form and how it comes about. As a morphological operation, SA might hold the answer.

${ }_{7}^{7}$ The head 'B' represents the conjoiner head of a boolean phrase Munn (1993). 
3. Analysis. In the previous sections, I have laid out the examples of SA and the environment in question: conjunctions formed by $-(y) I p$. In this section, I first lay out the analysis of Kabak (2007) in more detail, then I re-evaluate some of its points, and finally I introduce -(y)Ip's relation to SA.

3.1 ANALYSIS OF SA. Kabak (2007) argues that SA is only licit with inflectional markers in both nominal and verbal constructions. The difference comes about in the morphological word-hood of what is left after suspension. Verbals are bound by a configuration of affixes to be a morphological word while nominals are not. I interpret the arguments of Kabak (2007) as concise constraints in (14).

(14) a. SA-MWORD: Suspended affixation is valid iff what is left is a morphological word.

b. MWORD: A verb is a morphological word iff it ends with a terminal suffix.

c. Terminal suffixes: $-A r / I r \sim[\mathrm{AOR}]$, - Iyor $\sim[\mathrm{PROG}],-m I S ̧ \sim[\mathrm{PRF}],-A c A K \sim[\mathrm{FUT}],-m A l I$ $\sim[\mathrm{NEC}]$, agreement suffixes

d. SA-RBound: Suspended affixation is rightward bound on affixes. The suspended affixes must constitute the uninterrupted right edge of the conjunct. SA is uninterrupted once it starts.

These constraints and the inventory of terminal affixes work to an extend without extra assumptions. The only particular point they miss is that agreement markers that come atop -DI $\sim$ PST and $-s A \sim$ COND are not suspendable as in (15). Kabak deals with this by making the assumption 'Turkish speakers need to recuperate a person agreement marker when processing verbal constructions as morphological words.' This does not solve the problem straightforwardly since other aspectual markers like -Iyor do not need this assumption. It is only the PST and the COND that require this.

(15) Ev-e git-ti-*(m) ve uyu-du-m.

house-DAT go-PST-1SG AND sleep-PST-1SG

'(I) went home and slept.'

To ground this assumption into the way that SA works, I explicitly propose that SA targets terminal nodes in syntax (16). Unsuspendability of the agreement markers atop PST and COND come out naturally this way if they are inserted to one terminal node. ${ }^{8}$

a. SUSPEND: Suppress exponent insertion for terminal nodes.

b. Terminal nodes: $\mathrm{C} \sim$ [z-paradigm, stacked TAM (tense, aspect, modality) markers], T $\sim$ [k-paradigm, PST, COND, AOR, FUT, PROG, PRF, NEC]

Independent evidence for this description of terminal nodes and insertion can come from linearization behaviour of the agreement paradigms with regards to the question clitic $(=m I \sim Q)$. Insertions in ' $\mathrm{C}$ ' linearise to the right of this clitic and insertions in ' $\mathrm{T}$ ' linearise to the left of it as in (17) and (18), an observation noted in the literature before with a different analysis (Kahnemuyipour \& Kornfilt, 2011; Sezer, 2002). This view of insertion and terminal nodes also explains why PST, COND, and k-paradigm agreement markers are suspendable if they are stacked on other aspectual markers (18). ${ }^{9}$

\footnotetext{
${ }^{8}$ I assume multiple exponents can be inserted in a single node.

${ }^{9}$ Square brackets '[]' indicate deleted material, parentheses '()' indicate optionality
} 
a. z-paradigm, right of $\mathrm{Q}$

Ev-e gid-iyor =mu-yum?

house-DAT go-PROG =Q-1SG

'Am (I) going home?' b. k-paradigm, left of Q

Ev-e git-ti-m =mi?

house-DAT go-PST-1SG =Q

'Did (I) go home?'

(18) Stacked markers, right of Q

Ev-e gid-iyor-[du-m] ve yat-1yor =mu-y-du-m?

house-DAT go-PROG-[PST-1SG] AND sleep-PROG =Q-COP-PST-1SG

'Was (I) going home and sleeping?'

3.2 ANALYSIS OF - $(y)$ Ip. The constraints shown or proposed so far are numerous, and it could be better if one were to attribute some of these constraints to other parts of the grammar besides SA. In this subsection, my aim is to show that the morphological word constraint can be separated from SA if $-(y) I p$ is evaluated as an interacting factor with SA and an exponent for AND inserted under contextual allomorphy.

I propose that the difference between $v e$ and $-(y) I p$ comes about in vocabulary insertion after suspension. As far as syntax is concerned there is only AND. If what is left after suspension is a morphological word then $v e$ and if what is left after suspension is a non-morphological word then $-(y) I p$ is inserted. The insertion rule for AND is given in (19) and Figure 1 illustrates the process. ${ }^{10}$

$$
\text { AND } \leftrightarrow-(y) I p / \text { Non-MWord +_- } \mid \text { elsewhere ve }
$$

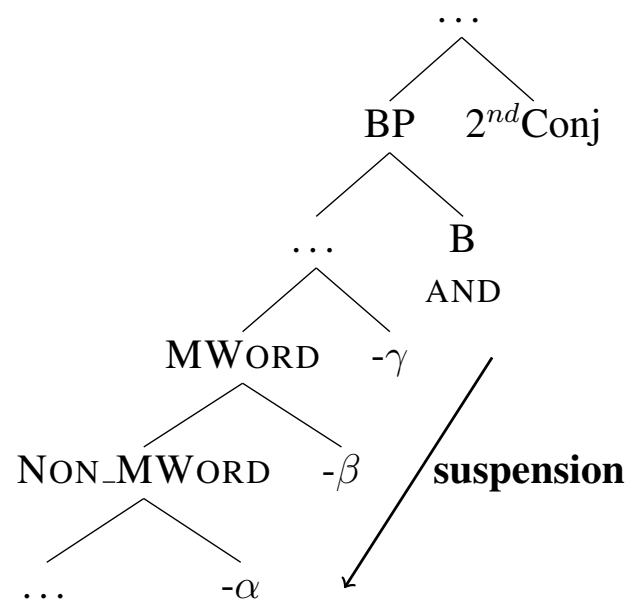

Figure 1: Initial analysis of SA

As a result of taking ve and -(y)Ip as exponents of AND inserted under contextual information, and the contextual information being the morphological word status, I have removed the morphological word as a constraint for SA and placed it in the vocabulary insertion for AND. This enables to have a unified view for the exponents $v e$ and $-(y) I p$. It also reduces the number of constraints operating on SA. As a result, the effect of the morphological word is still in the grammar, but it is now an interaction of SA and vocabulary insertion leading to the differences in the suspension of verbal affixes.

\footnotetext{
${ }^{10}$ The arrow direction is for illustrative purposes, not for the derivational order
} 
A welcomed prediction of this analysis is ambiguity. The ambiguous scope environment provided in (11c), repeated below as (20), can be modeled in a unique way with the analysis at hand. Both readings start at syntax as different structures. The string for NEG-FUT and the string for FUT constitute the rightmost affixes in each structure. SA is carried out in both of them up to the verb and in both of them what is left is not a morphological word so $-(y) I p$ is inserted for the conjoiner AND. This way, two distinct derivations in the syntax output one and the same surface form $(21) .^{11}$

Bugün çalış-1p yarın git-me-yecek.

today work-PC tomorrow leave-NEG-FUT[3SG]

1: 'S/he will not work today and will not leave tomorrow.'

2: 'S/he will work today but will not leave tomorrow.'

\begin{tabular}{|c|c|c|c|c|c|c|}
\hline \multirow[b]{2}{*}{ 1: } & \multicolumn{2}{|c|}{ Syntax output (what LF sees) } & \multirow[b]{2}{*}{$\Rightarrow$} & SA & \multirow{3}{*}{$\begin{array}{l}\Rightarrow \\
\Rightarrow\end{array}$} & $\mathrm{VI}$ \\
\hline & V-NEG $1-\mathrm{FUT}_{1}$ & AND V-NEG-FUT & & $\mathrm{NEG}_{1}-\mathrm{FUT}_{1}$ & & $\mathrm{~V}-(y) \operatorname{Ip}$ \\
\hline 2: & $\mathrm{V}-\mathrm{FUT}_{2}$ & AND V-NEG-FUT & $\Rightarrow$ & $\mathrm{FUT}_{2}$ & & $\mathrm{~V}-(y) \operatorname{Ip}$ \\
\hline
\end{tabular}

Surface (PF) output: ‘V-(y)Ip V-NEG-FUT' $\leftrightarrow(1,2)$

An additional constraint that can, sort of, be changed is SUSPEND-RBound. If one takes $\mathrm{SA}$ as a process that is turned on and off per derivation, it should be an operation that can only be turned off when a derivation ends and not before it. This would explain why, in multiple conjunct environments, SA has to be performed for all but the last conjuncts (22). This shows that SA is not only bound by a periphery per verb but also per derivation. As a result, the remaining constraints for SA are the following in (23). Depending on the language, suspension can be rightward or leftward bound per verb.

defter, kalem- $(* \mathrm{i})$, ve kitab-1

notebook pencil-(*ACC) AND book-ACC

'The notebook, the pencil, and the book'

a. SUSPEND

Suspension can only target terminal nodes.

b. SUSPEND-XBOUnd

Suspension is performed per derivation (the whole conjunction) and it is X-bound per verb.

As a general summary of the data and the analysis, I have shown that the environment created by $-(y) I p$ is a conjunction. I have unified the analysis for $-(y) I p$ and $v e$ as exponents for AND by relating the insertion to SA. This resulted in reducing the number of constraints operating directly on SA and removed a syntactic distinction between $-(y) I p$ and $v e$. The remaining discussion is about what a morphological word is.

4. Discussion. Until this point, I have not taken a position on what could be the natural class for a morphological word. I am using what Kabak (2007) proposed as terminal suffixes to form a morphological word and I treat the remaining affixes as extending a non-morphological

\footnotetext{
${ }^{11}$ Here LF stands for the logical form where syntactic structure is interpreted in parallel to the formation of the surface form. Meaning that there is a Y model of language.
} 
word. The demarcation for morphological word can follow from (i) a notion of phase and head movement in Turkish (Fenger, 2020), or (ii) root extension and phases within words (Marantz, 2007). In the following subsections I discuss both options and lay out some predictions.

4.1 HeAd MOVEMENT AND PHASES. If word building is attributed to syntax and carried out by head movement, there could be a point where it is interrupted. Fenger (2020) exactly points this out for Turkish. This would not only predict how much SA you can perform with the conjoiner ve but also some behaviours of affixes. In Turkish, when tense and aspect markers are stacked, an optional behaviour arises. The copula that has a zero form in between the markers can have a free form (24).

a. Zero copula

dur-uyor-du-m.

stand-PROGCOP-PST-1SG

'I was standing.' b. Free copula dur-uyor i-di-m. stand-PROG COP-PST-1SG 'I was standing.'

In this analysis, some aspectual heads are phase boundaries (Chomsky, 2001) and head movement can not proceed further. That is why, for further inflections, a copula is inserted. This would explain SA if we only consider the environment formed by ve, and not $-(y) I p$.

If one were to assume head movement demarcated by phase in Turkish, the only analysis left for $-(y) I p$ would be a small conjunction analysis before an aspectual head. This would obviate the need for a morphological word constraint for SA. This time, however, there should be a ban against SA within the phase demarcated by the aspectual head. Meaning that SA should start after the phase demarcated by the aspectual head. This is not the case, SA can be performed on the internal argument of a verb (25) which would be within the aspect phase in question. If this is to be avoided, it should be explicitly stipulated that 'SA is banned for verbs within the phase demarcated by the aspectual head.'

\section{kalem ve kitab-1 al-miş.} pencil AND book-ACC buy-PRF

'S/he bought the pencil and the book.'

SA analysis with head movement and phase could work but it works at the expense of having a very specific stipulation, lack of uniformity for the exponents ve and $-(y) I p,{ }^{12}$ and the lack of ambiguity analysis for (20). I argue that it would be more preferable to have a unified analysis for ve and $-(y) I p$ with a more free SA operator, and still account for the empirical points made so far.

4.2 ROOT EXTENSION AND WORD PHASES. If the understanding of phase in terms of syntax is not preferred, another option would be to assume that morphemes have late insertion but some morphemes do not alter the root in the same way as others. The problem at hand is how to put the morphological and non-morphological word in a more theoretical footing. This could be achieved through 'inner' and 'outer' suffixes (Marantz, 2007). Much like the phases in syntax, combination of a root and some affixes can result either in the extension of the root or culmination of its category. In Figure 2, the affix $X$ and below represent the 'inner' affixes and the affix $\mathrm{Y}$ and above represent the 'outer' affixes.

\footnotetext{
${ }^{12}$ Keep in mind that I am pursuing a conjoiner analysis for both exponents ( $v e$ and $\left.-(y) I p\right)$. If $-(y) I p$ is taken as an adverbial, this is no longer an issue.
} 


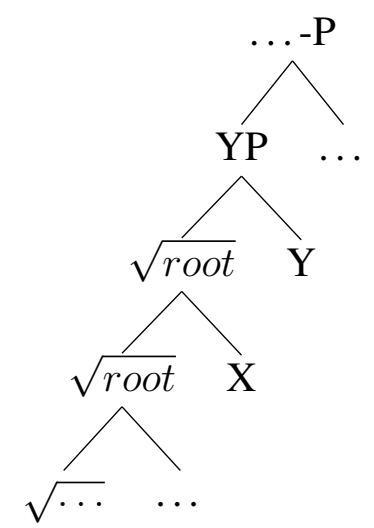

Figure 2: Word phases representation

The crucial part is that some affixes extend the root while others do not. This doesn't necessarily mean an affix is always a root extender or always assigns category, which is clearly put forward in Marantz (2007). Here, I treat the affixes that can reside under '- $(y) I p$ ' as root extending, or non-category influencing affixes stated in (26).

(26) Root extenders: -Ábil $\sim \mathrm{ABIL},\left(. V_{\text {. }}\right)-\mathrm{mA} \sim \mathrm{NEG},-$ Íver $\sim \mathrm{CON},-$ Ákal $\sim \mathrm{CONT},-A ́ d u r \sim \mathrm{DUR}$

These affixes belong to the set of affixes leading to exceptional stress patterns in Turkish (Inkelas, 1999; Inkelas \& Orgun, 2003; Kabak \& Vogel, 2001; Özçelik, 2014). Unfortunately, this doesn't mean that exceptional stress pattern is a tell of inner and outer affix status, another exceptional stress affix -Íyor (PROG) is not followed by $-(y) I p$ in a conjunction. There is only a one way relation here, which is that inner affixes are always exceptionally stressed.

An argument against this analysis can be the exclusion of voice affixes from the description. They, too, seem to extend the root with no exceptional stress. I would argue that voice affixes do not constitute syntactic nodes in Turkish, and by SUSPEND, they are excluded from the consideration under suspended affixation.

A further observation against the argument can come from the seeming ability of some root extending affixes to have their uniformity broken by a focus particle like $=D A(=\mathrm{FOC})$. These affixes are -Ábil $\sim \mathrm{ABIL},-I ́ v e r \sim \mathrm{CON},-A ́ k a l \sim \mathrm{CONT}$, and $-A ́ d u r \sim \mathrm{DUR}$. A focus particle can come right after the harmonizing vowel and disrupt affix uniformity, and its position can cause a mild focus change (27). This can not solely be attributed to a stress-based placement of the focus particle since it can vary in position leading to different scope.

$$
\begin{aligned}
& \text { a. Ev-e gid-ebil-ir =de } \\
& \text { house-DAT go-ABIL-AOR =FOC } \\
& \text { 'He CAN go home too.' }
\end{aligned}
$$

b. Ev-e gid-e =de-bil-ir house-DAT go-ABIL g $_{1}=$ FOC-ABIL $_{1}$-AOR 'He can GO home too.'

It needs to be noticed, however, that the affixes that can have their uniformity violated by $=D A \sim$ FOC have their free standing parts as free words in Turkish. (bil 'to know,'ver 'to give,' kal 'to stay,' and dur 'stop'). Another affix that looks like these with regards to stress is Iyor $\sim$ PROG. The focus particle $=D A \sim$ FOC can not intervene between the harmonizing vowel and the rest of the affix, but there is a regional dialect spoken in and around Isparta (behind Taurus mountains, middle Mediterranean region) where the question clitic $=m I$ can indeed disrupt the uniformity of -Iyor $\sim$ PROG (28). 
Dialectal variation

Memleket-e gid-i =mi-yo-n?

home_town-DAT go-PROG $1=$ Q-PROG $1-2 \mathrm{SG}$

'Are you going to your hometown?'

As a result of the discussion in this section, it is not entirely clear if one can come up with a phonological reflex of a natural affix class for the affixes in (26). A phase analysis in syntax requires very specific assumptions that bar the operation of SA. Word phases with inner and outer affixes fail to have a natural class of affixes to define as inner or outer.

An analysis of the stress assignment can be argued for in the grounds of compound formation (except for the negation affix), with the harmonizing vowel belonging to an inflectional affix and the rest of the affix as free standing words (with yor as a diachronic equivalent of yürü 'to walk'). A similar pattern of inflectional affix plus a synchronic verb is illustrated in Fenger (2020). The most promising analysis would be in line with assuming the harmonizing vowels as inflection markers, only surviving in these affixes and the non-harmonizing separable parts as free words. This would be the analysis of compound formation and it would both explain the stress pattern, since in Turkish compounds leftmost phonological word is stressed (1 2), and the 'root extension' property of these affixes (to the exclusion of -Iyor which lacks a synchronic free word, and not followed by $-(y) I p$ as a conjoiner). The stress pattern of -Iyor is argued through diachronic change by Schiering (2006) but a synchronic one can be maintained for the affixes in (26) except the negation marker.

5. Conclusion. In this study, I argued that the Suspended Affixation (SA) in Turkish needs to be considered with an additional conjoiner: $-(y)$ Ip. I showed that it takes fewer assumptions to treat $-(y) I p$ like a conjoiner in syntax and derive its surface form as an allomorphic version of ve. My analysis reduces the constraints operating on SA and unites the conjoiner analysis of AND for Turkish. This maintains a single conjoiner analysis in syntax and derives the surface forms post syntactically. The morphological word constraint proposed for SA (Kabak, 2007) now regulates the vocabulary insertion for AND. After the words with a morphological word status, $v e$ is selected and after the words with non-morphological word status $-(y) I p$ is inserted. As one of the reviewers rightfully pointed out, there is a clear prediction of the proposed analysis: Any exponent(s) shown to constitute a syntactic node can be targets of SA. However, there should be limits to what can actually stand behind, if we assume there are exponents stripped of categories, and categories provided by additional exponents (Marantz, 1997). Can those be subject to SA? Surely, there needs to be a more basic ban against realizing 'bare' exponents (e.g. roots) in grammar so that basic units that assign or change categories do not become subject to SA like those of derivational affixes.

Arguments for coming up with a natural class of affixes to form a morphological word or a non-morphological word is difficult using the approaches of syntactic word formation with syntactic phases as barriers (Fenger, 2020) or morphological word phases with inner and outer affix distinctions (Marantz, 2007). A more approachable analysis is the root extending affixes forming a compound, thereby explaining their exceptional stress patterns and root extension status. There are supporting empirical points for the compound analysis by the uniformity breaking $=D A$ particle and a regional dialect variant. 


\section{References}

Akkuş, Faruk. 2019. Dative arguments in Turkish: Caused experiencers versus applicatives. In Proceedings of the workshop on turkic and languages in contact with turkic, vol. 4 1, 1-13.

Akkuş, Faruk. 2016. Suspended affixation with derivational suffixes and lexical integrity. Mediterranean Morphology Meetings 10. 1-15. https://doi.org/10.26220/mmm.2720.

Broadwell, George Aaron. 2008. Turkish suspended affixation is lexical sharing. In Miriam Butt \& Tracy Holloway King (eds.), Proceedings of the lfg08 conference, 198-213. Stanford, CA: CSLI publications.

Chomsky, Noam. 2001. Derivation by phase. In Michael Kenstowicz (ed.), Ken hale. a life in language, 1-52. MIT Press, Cambridge, Mass.

Cinque, Guglielmo. 1999. Adverbs and functional heads: A cross-linguistic perspective. Oxford: Oxford University Press.

Cinque, Guglielmo. 2002. A note on mood, modality, tense and aspect affixes in Turkish. In Eser Erguvanlı Taylan (ed.), The verb in turkish, 47-59. Amsterdam: John Benjamins Publishing Company. https://doi.org/10.1075/la.44.03cin.

Demir, Duygu Özge. 2014. Adverbial clauses in modern Turkish. In Öner Özçelik \& Amber Kennedy Kent (eds.), Proceedings of the 1st conference on central asian languages and linguistics, 73-78. Indiana University, Bloomington, IN.

Erschler, David. 2012. Suspended affixation in Ossetic and the structure of the syntaxmorphology interface. Acta Linguistica Hungarica (Since 2017 Acta Linguistica Academica) 59(1-2). 153-175.

Erschler, David. 2018. Suspended affixation as morpheme ellipsis: Evidence from Ossetic alternative questions. Glossa: A Journal of General Linguistics 3(1). 12. https://doi.org/10.5334/gjgl.501.

Fenger, Paula. 2020. Words within words: The internal syntax of verbs. Storrs, CT, USA: University of Connecticut dissertation.

Fokkens, A, L Poulson \& EM Bender. 2009. Inflectional morphology in Turkish VP coordination. In Stefan Müller (ed.), Proceedings of the 16th international conference on headdriven phrase structure grammar, 111-130. Stanford, CA: CSLI publications.

Göksel, Aslı \& Celia Kerslake. 2004. Turkish: A comprehensive grammar. Abingdon: Routledge. https://doi.org/10.4324/9780203340769.

Guseva, Elina \& Philipp Weisser. 2018. Postsyntactic reordering in the Mari nominal domain. Natural Language \& Linguistic Theory 36(4). 1089-1127. https://doi.org/10.1007/s11049018-9403-6.

Inkelas, Sharon. 1999. Exceptional stress-attracting suffixes in Turkish: representations versus the grammar. The prosody-morphology interface 79. 134.

Inkelas, Sharon \& Cemil Orhan Orgun. 2003. Turkish stress: a review. Phonology 139-161.

Johanson, Lars. 1995. On Turkic converb clauses. Haspelmath \& König (eds.) 1995. 313-348.

Kabak, Baris \& Irene Vogel. 2001. The phonological word and stress assignment in Turkish. Phonology 315-360.

Kabak, Barış. 2007. Turkish suspended affixation. Linguistics 45(2). 311-347. https://doi.org/10.1515/ling.2007.010.

Kahnemuyipour, Arsalan \& Jaklin Kornfilt. 2011. The syntax and prosody of Turkish "prestressing” suffixes. Interfaces in linguistics: New research perspectives 205-221. 
Kornfilt, Jaklin. 1996. On some copular clitics in Turkish. ZAS Papers in Linguistics 6. 96-114. Kornfilt, Jaklin. 1997. Turkish. Abingdon: Routledge.

Kornfilt, Jaklin. 2012. Revisiting "suspended affixation" and other coordinate mysteries*. In Laura Brugé, Anna Cardinaletti, Giuliana Giusti, Nicola Munaro \& Poletto Cecilia (eds.), Functional heads: The cartography of syntactic structures, 181-196. Oxford: Oxford University Press.

Kratzer, Angelika. 1996. Severing the external argument from its verb. In Phrase structure and the lexicon, 109-137. Springer.

Lewis, Geoffrey. 1967. Turkish grammar. Oxford: Oxford University Press.

Marantz, Alec. 1997. No escape from syntax: Don't try morphological analysis in the privacy of your own lexicon. University of Pennsylvania working papers in linguistics 4(2). 14.

Marantz, Alec. 2007. Phases and words. In Sook-Hee Choe (ed.), Phases in the theory of grammar, 191-222. Dong-In Publishing Company.

Munn, Alan. 1993. Topics in the syntax and semantics of coordinate structures. College Park, MD, USA: University of Maryland at College Park dissertation.

Orgun, Cemil Orhan. 1995. Flat vs. branching morphological structures: The case of suspended affixation. Annual Meeting of the Berkeley Linguistics Society 21. 252-261. https://doi.org/10.3765/bls.v21i1.1394.

Özçelik, Öner. 2014. Prosodic faithfulness to foot edges: the case of Turkish stress. Phonology 229-269.

Pounder, Amanda. 2006. Broken forms in morphology.

Pylkkänen, Liina. 2008. Introducing arguments, vol. 49. MIT press.

Ross, John Robert. 1967. Constraints on variables in syntax. Cambridge, MA, USA: Massachusetts Institute of Technology dissertation.

Schiering, René. 2006. Morphologization in Turkish: Implications for phonology in grammaticalization. In Proceedings of the 13th international conference on Turkish linguistics, .

Sezer, Engin. 2002. Finite inflection in turkish. In Eser Erguvanlı Taylan (ed.), The verb in Turkish, vol. 44, 1. Amsterdam: John Benjamins Publishing Company. https://doi.org/10.1075/la.44.02sez.

Underhill, Robert. 1976. Turkish grammar. Cambridge, MA: MIT press.

Yoon, James Hye Suk. 2017. Lexical integrity and suspended affixation in two types of denominal predicates in Korean. Glossa: A Journal of General Linguistics 2(1). 45. https://doi.org/10.5334/gjgl.248. 